\title{
装配式建筑工程管理的影响因素与对策
}

\author{
张玉林
}

浙江嘉宇工程管理有限公司

DOI:10.32629/btr.v1i5.1637

[摘 要] 在建筑行业当中,装配式建筑在工程施工方面具有一定的系统性和复杂性,会涉及到诸多工序,因此,在施工当中可能 会出现各种各样的质量问题或安全隐患问题, 而这些问题不仅关系到建筑行业的发展,同时还会对人们的生活水平造成相应的 影响, 而为了确保建筑行业的可持续发展, 必须要对其工程管理工作进行不断的强化, 只有如此,才能为建筑行业的发展提供驱 动力, 所以,文章围绕装配式建筑中的工程管理进行讨论,对装配式建筑进行深入的了解, 明确其工程管理过程中的相关影响因 素,并对强化工程管理的具体措施加以探讨和描述,希望能够使装配式建筑的工程管理水平得到进一步的提升。

[关键词] 装配式建筑; 工程管理; 影响因素; 对策

在近些年当中, 以先进设计理念、新型材料以及新技术 为基础的生产方式逐渐成为建筑行业实现产业化发展的重 要趋势, 而这种建筑产业化是我国建筑行业未来发展过程中 必须要重点关注的问题, 同时也是工程管理人员工作过程中 需要面对的新常态, 特别是对装配式建筑而言, 这种建筑模 式具有工期短、能耗低、成本投入少等诸多优势, 逐渐获得 了建筑领域的青棟, 在装配式建筑当中有效落实工程管理工 作, 能够对建筑产业化的发展产生很大的推动作用, 同时也 是相关人员的重要使命, 因此, 针对装配式建筑中的工程管 理工作进行深入的研究是很有必要的。

\section{1 浅析装配式建筑}

1.1 设计多样化

随着人们生活质量的提升, 人们对于自身居住条件的要 求越来越高, 这使得传统形式的建筑已经无法满足人们的使 用需求, 特别是建筑当中存在过多的承重墙, 导致空间分隔 受到严重的限制, 开间偏小, 难以保证室内空间分隔的合理 性, 而对装配式建筑来说, 其能够对内部空间进行自由的分 隔, 能够对居住者的多样化设计需求加以满足, 应用轻质隔 墙, 不管是大厅小居室还是小厅大居室的设计要求都能够得 到很好的满足, 大大提升了建筑空间设计的自由性。

\section{2 功能科技化}

在装配式建筑当中, 具有多种科技化功能, 涉及到保温、 隔声等功能, 其墙体设有保温层, 能够对噪声进行有效的吸 收, 而且门窗和墙体之间连接空隙较小, 能够有效减少外部 环境噪声的进入, 具有提升室内舒适性的作用, 此外, 装配式 建筑的具有较强的节能功效, 其保温层的温度隔绝作用能够 降低夏季空调消耗和冬季采暖消耗, 而且整体结构防火性能 良好, 其中应用的材料具有难燃、阻燃的特点, 可以有效减少 火灾问题的产生概率。

\section{3 生产工厂化}

装配式建筑当中的外墙板可以在工厂当中使用模具进 行生产, 通过对外墙板的喷涂和烘烤能够使其美观性大大提 升, 并且不会有褪色问题的产生, 在近些年当中, 传统建筑中
应用的门窗得到了有效的优化, 而在利用各种先进技术能够 在工程当中对各种金属及连接件进行生产, 各种室内材料都 可以在工程流水线上进行生产, 而且生产过程中, 能够对材 料的隔声、防火以及保温等性能进行灵活的调节 ${ }^{[1]}$ 。

\section{2 装配式建筑工程管理中的影响因素}

\section{1 构配件因素}

在装配式建筑当中, 会涉及到许多的构配件, 这些构配 件受到功能、使用区域等因素的影响, 存在多种多样的特点, 而这些构配件的管理工作则会对工程质量造成直接的影响, 在对装配式建筑进行工程管理的过程中, 其楼板、楼梯以及 剪力墙等主要结构都需要应用构配件进行拼装, 而这些构建 一般会由特定厂家进行统一生产, 而就我国目前的构配件生 产情况来看, 这种专门针对装配式建筑进行构建生产的工厂 还比较少, 而且工厂规模也比较有限, 在装配式构件生产方 面存在经验不足的问题, 导致市场当中的构配件质量参差不 齐, 与此同时, 装配式建筑的施工现场与构配件工厂都会有 一定的距离, 所以在对构配件进行运输的过程中, 需要采用 专用测量进行运输, 并且要在运输工程中做好构配件的保护 工作, 在构配件运到施工现场以后, 还要对其进行科学的存 放、管理和养护, 避免受到环境或人为等因素的影响出现受 损问题, 对建筑质量造成不利影响, 此外, 如果在出场过程中 不能生产构配件的材料质量进行科学的检测, 导致不合格的 构配件进入施工现场, 或者是合格构配件未能得到合理的保 养和应用, 同样会对工程质量造成影响 ${ }^{[2]}$ 。

\section{2 施工准备因素}

施工准备是影响装配式建筑工程管理效果的重要因素, 在该阶段当中, 施工企业需要具备一定的预见性, 确保质量 规划的科学性及合理性, 要认识到构配件管理和规划对装配 式建筑工程管理的影响, 此外, 在对装配式建筑进行工程管 理的过程中, 施工机械质量、基础设施调配以及施工人员综 合素质都会对管理质量造成一定的影响, 而对施工方案以及 质量规划防范进行科学的编制, 对装配式建筑工程管理工作 的有序开展具有非常积极的作用 ${ }^{[3]}$ 。 


\section{3 管理协调因素}

与传统形式的现浇式建筑相比, 在技术方面, 装配式建 筑获得了长足的发展, 也正是因为这种形式的建筑在技术层 面上获得了较大的突破, 使得此类建筑在组织管理方面的要 求也变得越来越高, 这就需要施工企业进行多方协调, 包括 与设计单位就图纸和技术进行协调; 与构配件生产厂家加强 质量协调; 针对工程质量对业主和监理单位进行协调等, 以 此来保证工程施工的顺利开展, 除此之外, 施工企业还要安 排专业人员做好技术交底和质量跟踪等工作, 同时要对相关 反馈工作加以落实, 由施工企业根据反馈信息进行适当调整, 使装配式建筑方面的工程管理效果得到有效的保障 ${ }^{[4]}$ 。

\section{3 装配式建筑强化工程管理工作的具体措施}

3.1 对生产质量加强管理

在对装配式建筑的生产过程进行质量安全管理的过程 中, 要对以下工作加以落实: 第一, 要做好施工人员的管控工 作, 因为施工人员是影响装配式建筑质量的主要因素之一, 如果不能确保施工人员的专业水平, 非常容易对施工工序以 及相关操作流程的完善性造成不利影响, 从而引发诸多问题, 例如, 装配式建筑的保护层厚度、平整度以及构件尺寸与设 计要求不符, 未能对相关构配件进行严格的检验, 导致质量 不过关的产品流入到市场当中; 第二, 在生产原材料方面, 如果入模之前未能对混凝土配比进行科学的控制, 会对装配 式建筑构配件质量造成直接的影响。而构配件的相关生产工 艺, 与构配件质量具有非常密切的关联, 但在实际施工工艺 中还有很多问题存在, 例如, 相比于传统形式的现浇结构, 虽 然工厂化的构配件生产方法能够使胀模概率有效降低, 但在 工艺方法的影响下, 会使模板之间存在较大缝隙, 对建筑质 量安全以及整体美观性造成不利影响, 所以在混凝土建筑过 程中, 需要对够构配件问题进行严格的审查, 通过对高精度 定位工具的有效应用, 做好模板尺寸的定位工作, 并确保对 拉螺栓能够保持松紧一致 ${ }^{[5]}$ 。

\section{2 做好运输管理工作}

在对装配式建筑进行工程管理的过程中, 应该将构配件 方面的运输管理工作做好, 需要对特制的运输架加以应用, 完成装配式建筑构件的有效运输, 确保运输的安全性, 首先 要将完成加工的构配件放在运输架上, 然后降低拖车高度,
运用倒车的方式将运输架装载至运输车辆当中, 在此过程中 需要对运输车提升的高度加以保证, 并通过智能机械手臂对 构配件进行侧向支撑, 使运输工作能够具有较高的安全性, 以此来确保构配件的运输质量 ${ }^{[6]}$ 。

3. 3 对建筑工程的相关管理体系加以完善

当前阶段, 装配式建筑在工程管理体系方面还有待提升, 需要从多方面入手做好完善工作, 不仅要对国内外较为先进 的管理理念及方法进行学习和借鉴, 确保装配式建筑工程管 理工作的全面性和系统性, 并根据我国建筑行业发展的实际 情况, 对管理体系进行科学的构建, 同时还要对相关管理部 门进行优化调整, 确保权责分明, 保证各个部门能够对自身 责任进行有效的落实, 通过对分配制度以及用人制度的有效 强化, 使工程工作能够获得一定的人才支撑, 从而为管理质 量的增强提供保障 ${ }^{[7]}$ 。

\section{4 结语}

综上所述, 工程管理工作是确保装配式建筑质量安全的 重要工作, 对其进行落实, 能够使工程质量得到有效的提升, 因此, 相关单位在对装配式建筑进行工程管理的过程中, 一 定要对其中的影响因素加以明确, 以此为基础, 对各项管理 工作加以落实, 使装配式建筑质量能够满足社会各界的需 求。

\section{[参考文献]}

[1]郭天荣.浅析装配式建筑工程管理的影响因素与对 策[J].中国房地产业,2018,5(26):120。

[2]李可富.装配式建筑工程管理的影响因素与对策 [J]. 建筑工程技术与设计,2018,6(20):3304.

[3]海涵.浅析装配式建筑工程管理的影响因素与对策 [J].建筑工程技术与设计,2018,8(20):3424.

[4]丁思康.装配式建筑工程管理的影响因素与对策 [J]. 建筑工程技术与设计,2018,2(20):472.

[5]胡泽宇.浅析装配式建筑工程管理的影响因素与对策 [J].门窗,2018,2(1):64-65.

[6]丁国梁.装配式建筑工程管理的影响因素与对策研究 [J].价值工程,2018,4(28):11-12.

[7]赵天祥.装配式建筑工程管理的影响因素与对策探究 [J]. 商品与质量,2017,3(4):145. 